
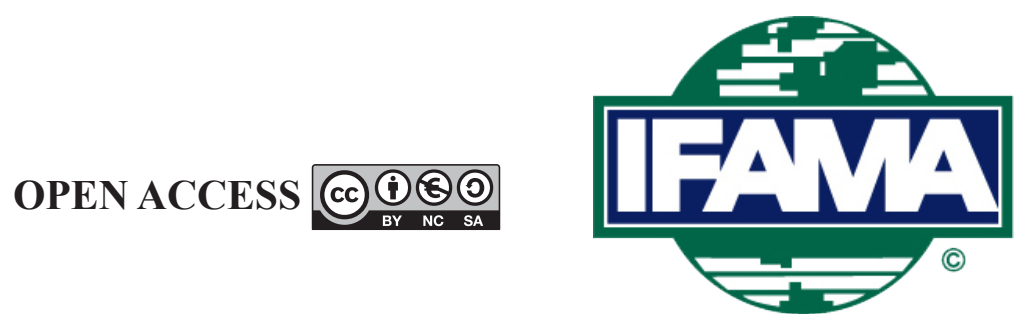

International Food and Agribusiness Management Review

Volume 23, Issue 1, 2020; DOI: 10.22434/IFAMR2019.0033

Received: 11 March 2019 / Accepted: 13 June 2019

\title{
Dynamic impacts of farm-level technology adoption on the Brazilian dairy supply chain
}

\author{
RESEARCH ARTICLE \\ Andre Rozemberg Peixoto Simões ${ }^{\circledR a}$, Charles Frederick Nicholson ${ }^{\mathrm{b}}$, Andrew M. Novakovic ${ }^{\mathrm{c}}$, \\ and Roberto Max Protil ${ }^{\mathrm{d}}$ \\ ${ }^{a}$ Adjunct Professor, Universidade Estadual de Mato Grosso do Sul, Aquidauana- \\ MS. Rodovia Aquidauana-UEMS km 12, Aquidauana-MS, Brazil \\ ${ }^{b}$ Adjunct Associate Professor, ${ }^{c}$ The E.V. Baker Professor of Agricultural \\ Economics, Charles H. Dyson School of Applied Economics and Management, \\ Cornell University, 451 Warren Hall, Ithaca-NY, USA \\ ${ }^{d}$ Adjunct Professor, Departamento de Economia Rural, Universidade Federal de \\ Viçosa. Avenida Purdue, Edifício Edson Potsch Magalhães Viçosa-MG, Brazil
}

\begin{abstract}
Agricultural technology adoption that increases individual firm productivity is generally assumed to improve competitiveness and profitability. However, technology that is adopted by many firms in an industry can shift the basic supply relationship, increasing total production while lowering farm prices. While generally beneficial to consumers, this result can reduce (or completely offset) benefits for farmers, especially late or non-adopters. Our objective is to assess the market dynamics of alternative assumptions about exogenous productivity-enhancing technology adoption by Brazilian dairy farms. Of particular interest is the distributional impact on farm incomes and on the proportion of milk production for different farm size classes. To achieve this objective, we developed an empirical System Dynamics model that evaluates market and farm profitability impacts from 2006 to 2016. We simulated six counterfactual scenarios comprising three rates of adoption (slow, medium and fast) by two farm size categories (small and large). Technology adoption impact differs in the short- and long-term and depending on the assumed rates and farm sizes. Non-adopters of technology can experience lower incomes and a smaller production and income shares when other farms adopt. The underlying causal structure of farm profitability and the herd management decisions suffices to explain the potential market exclusion of non-adopting farms (especially small-scale farms) when others adopt.
\end{abstract}

Keywords: dairy, system dynamics, technology adoption, Brazil, milk supply JEL code: Q12, O33

\footnotetext{
(1)Corresponding author: andrerpsimoes@hotmail.com
} 


\section{Introduction}

Studies about innovation in agriculture have a long history and most studies indicate that technology adoption can increase productivity, competitiveness and farm income (Feder et al.,1985; Verner and Gubbels, 1967). Many studies of technology in agriculture analyze the correlates of adoption behavior based on farmer attributes (e.g. age, education, years farming, size, income) social interaction (e.g. network and communication) or the perceived benefits of the technology (Asres et al., 2012; Baumgart-Getz et al., 2012). Other scholars have analyzed the role of various constraints in the development and adoption process (Feder and Umali, 1993), some suggesting the need for an 'innovation systems' approach (Spielman, 2005). In lower-income country settings, assessments (often static, partial-budget analyses) of the likely profitability of new technologies and practices are common (Novo et al., 2013; Oliveira et al., 2015). In contrast, relatively few studies focus on the dynamic effects of technology adoption on aggregated market variables such as supply-demand balance, prices, farm profitability and changes in farm structure. Studies of dairy technology adoption in the US (Weersink and Tauer, 1990; Zepeda et al.,1991) indicate that widespread use of productivity-enhancing technologies would result in higher milk production, lower prices and negative impacts on profitability. Previous studies also suggest that the benefits of technology adoption will not accrue generally and entirely (or perhaps to any great extent) to farmers, and there may be counterintuitive effects on the farm sector or farm structure (Johnson and Ruttan, 1997; Parsons and Nicholson, 2017).

Although previous studies have examined the effect of technology adoption on economic performance of Brazilian dairy farms (Breitenbach, 2018; Camilo Neto et al., 2012; Campos et al., 2014; Novo et al., 2013) no previous study assesses the dynamic impacts of scaled-up technology adoption on aggregated market outcomes and farm-level profitability by farm-size categories. Additional knowledge of these impacts is relevant for industry decision makers from input suppliers to food retailers, and for government policy (e.g. support program) choices. Government agencies and private companies worldwide invest in agricultural technology development and diffusion (Fuglie et al., 2013), typically with the expectation that it will improve farm-level productivity and profitability. However, they may not fully appreciate the aggregated impacts if those technologies are widely adopted. These impacts can include basic and short-term outcomes such as those on prices and sales, but also longer-term and structural change dynamics with substantive implications for farm income distribution. These longer-term outcomes can be counterintuitive and thus difficult to anticipate without a formal dynamic analysis (Sterman, 2000).

Supply increases from productivity-enhancing technology adoption will lower prices ceteris paribus, which would offset at least to some extent the benefits of productivity enhancement. These offsetting effects will likely not be equally distributed among types and sizes of farms. Previous research (e.g. Parsons and Nicholson, 2017) on the dynamics of livestock technology adoption has suggested that adopters and larger farms would experience improved profitability whereas smaller non-adopting farms would probably exit in the long run. This agrees with the findings of Quiroga and Bravo-Ureta (1992) who noted that lower prices due to technology adoption tend to lead to larger and fewer dairy farms. These potential negative effects leave unanswered questions about what rates of technology adoption (and by which farms) would cause pernicious effects that would offset the potential benefits.

A further important question is the extent to which technology adoption by one category of farms affects the economic performance of other farms. Previous research has indicated that milk supply elasticities differ over-time (Bhattacharya et al., 2016; Bozic et al., 2014; Chavas and Klemme, 1986) and that supply and demand respond to market stimuli with delays. Thus, it would not be surprising to observe dynamically complex outcomes (patterns of behavior that differ in the short and long run) in response to the adoption of productivity-enhancing technologies by Brazilian dairy farms. These relevant questions can be addressed with a simulation modeling approach, providing relevant insights about the relationship between technology use and the behavior of milk prices in Brazil as suggested by Olaya (2015). 
Assessing the impacts of technology adoption is relevant for the Brazilian dairy industry due to the importance of this sector in the national economy and because of the gap between observed and potential productivity at the farm level that constrains the industry's global competitiveness. In recent years, Brazil has been the fourth-largest producer of cow's milk in the world, with annual production of 33 billion liters in 2016, behind only the United States (96 billion), India (77 billion) and China (37 billion) (FAO, 2018). Milk production occurs on 1.2 million farms ( $23 \%$ of all farms) that are widely dispersed throughout the country, reflecting a diverse set of social, cultural, and climatic factors (IBGE, 2017). As a result, dairy farms are heterogeneous in terms of technology adoption intensity and production scale (Silva et al., 2016; Simões et al., 2017; Telles et al., 2017). According to Gomes (2006) 'technological duality' is a prominent feature in Brazilian milk production because farmers using higher-productivity technology operate side by side with farmers using low-input, low-output systems with limited adoption of newer available technologies. As a result, structural heterogeneity at the farm level should be considered when assessing the likely of adoption of new technologies by individuals and the impact of diffusion on markets (Howley et al., 2012).

Thus, our main objective is to assess the market dynamics and the distributional impacts of alternative assumptions about exogenous technology adoption by Brazilian dairy farms. Of particular interest is the distributional impact on farm incomes and on the proportion of milk production for different farm size classes. To achieve this objective, we developed an empirical System Dynamics (SD) model that evaluates market and farm profitability impacts during 2006 to 2016.

\section{Methods}

\subsection{Model conceptual framework}

The SD simulation model used to address the research objectives is based on the generic commodity market model proposed by Sterman (2000) that is a generalization of the seminal model of hog cycles published by Meadows (1970). Further, the model structure draws from many components from the US dairy industry model developed by Nicholson and Stephenson (2010, 2014), with modifications in the relevant parameters and in some structures to represent more appropriately the production sector dairy product manufacturing, and product demand of the Brazilian dairy industry. The full model comprises 140 equations divided into three interconnected modules: (1) Farm Milk Supply with a herd aging chain and farm-level profitability; (2) Dairy Processing and Demand, including exports and imports of the most important products; and (3) the Milk Price Formation determining dairy product and farm prices. The model represents six farm-size categories with different production strategies and response parameters, an aggregated decision-making process for the manufacture of four aggregated dairy product types, price responsive aggregate demand that grows with increases in population and GDP, and exogenous dairy product imports and exports. A more comprehensive description of the empirical model and all equations are provided in Supplementary Chapter S1.

In the SD modeling process, a Causal Loop Diagram (CLD) describes what is termed the 'dynamic hypothesis', that is, a depiction of the hypothesized system structure that causes an observed dynamic behavior. The CLD provides a simplified representation of the basic stock-flow-feedback processes represented in the empirical model (Figure 1) and describes hypothesized potential system behaviors. Arrows with a positive polarity indicate that the variable at the origin of the arrow has a causal effect in the same direction on the variable pointed to (i.e. the partial derivative of the variable pointed to is positive with respect to the variable pointed from). A negative sign also implies a similar causality, but with the inverse direction of a causality (i.e. partial derivative is negative). The feedback loops formed by the arrows are of two types: reinforcing loops with positive feedback that tends to amplify any disturbance and to produce exponential growth, or Balancing loops which a negative feedback tends to move the system toward an equilibrium point or goal. Variables inside a box represent the main stocks (state variables) of the model and variables outside the loops represent exogenous inputs. The CLD indicates two key reinforcing (R1 and R2) and two key balancing loops (B1 and B2), each with important delays, represented by the two parallel bars in the middle of the arrows (Figure 1). 


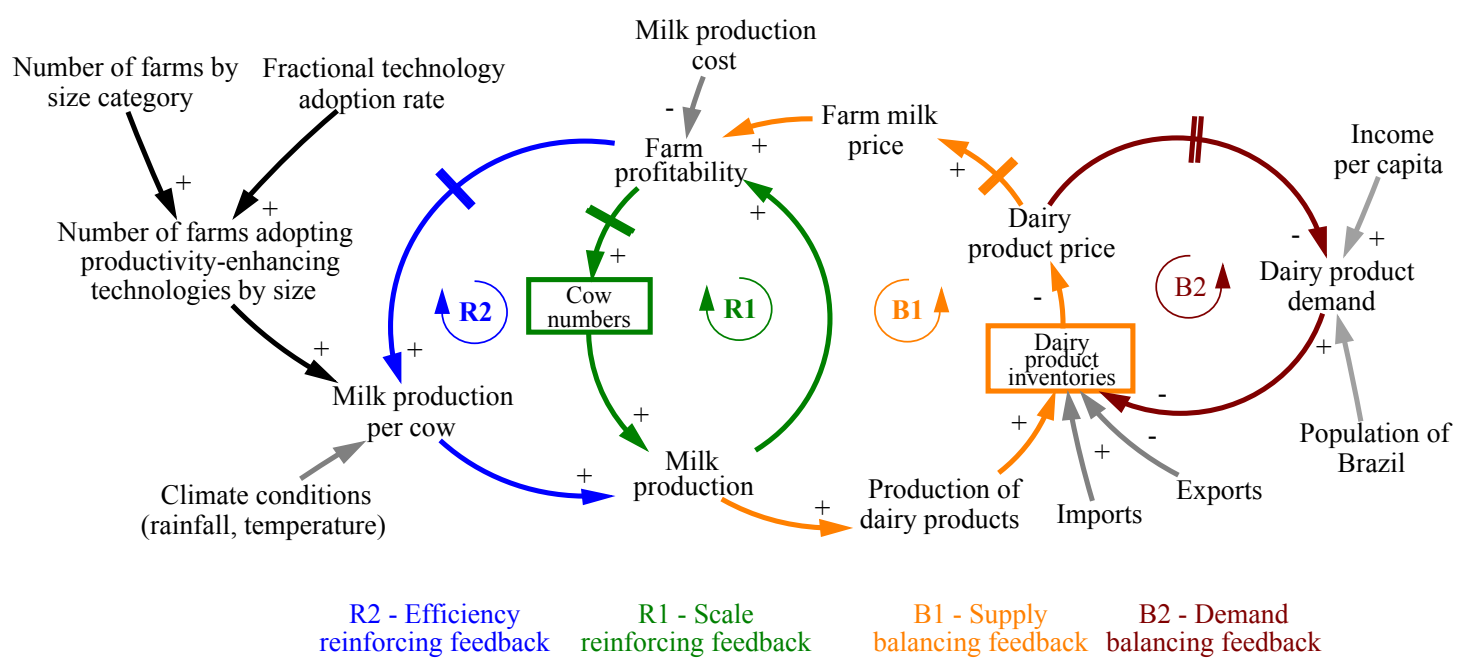

Figure 1. Causal Loop Diagram of the main stock-flow-feedback processes in the Brazil dairy supply chain model.

The rate of technology adoption ('fractional technology adoption rate') is assumed to vary by farm size (and scenario) and determines a key exogenous input, the 'number of farms adopting productivity-enhancing technologies'. The primary effect of adoption of technology is increasing 'milk production per cow' and consequently overall 'milk production'. Many analyses of technology adoption would consider short-run effects only to the point of increased milk production, without consideration of further relevant follow-on feedback effects. However, higher 'milk production' would increase 'farm profitability' and, with a delay due to both biological and economic factors, result in an increase in 'cow numbers' that also increases 'milk production'. This component of the system is thus a reinforcing feedback loop R1. Increased Farm Profitability also reinforces with a delay the initial effect of technology adoption on 'milk production per cow', through feedback loop R2. Thus, the initial effect of technology adoption on milk production is enhanced by two reinforcing feedback loops.

In addition to the reinforcing processes of exogenous technology adoption there are balancing effects that occur through changes to the relative supply and demand balance for milk and dairy products. Increased milk production will result in increased 'production of dairy products' and increased 'dairy product inventories'. Increased 'dairy product inventories' has a decreasing effect on 'dairy product price' and 'farm milk price' with a delay. A lower 'farm milk price' has a negative effect on 'farm profitability' that then also affects both 'cow numbers' and 'milk per cow'. These balancing effects have the potential to partially or completely offset the positive effects of the technology adoption on production and farm-level profitability, through loop B1. The effect of balancing loop B2 can help to offset the potential negative effects. Lower 'dairy product price' will positively affect 'dairy product demand', which will lower 'dairy product inventories' and have a positive influence on 'dairy product price' (and therefore, 'farm milk price' and 'farm profitability'). Therefore, the net effects on 'farm profitability' and the production outcomes overall and for each farm category will depend on which feedback loops dominate, the two reinforcing loops that enhance milk production or the balancing loops that lower farm milk prices. Note that without a quantitative simulation model representing these processes empirically, it is not possible to determine the direction or magnitude of changes in the outcomes with technology adoption.

Other exogenous factors are shown that affect both the supply and demand components in this conceptual model. Increases in 'milk production costs' would reduce 'farm profitability' (and thus 'milk production') and the 'climate conditions' can affect the 'milk production' (primarily through impacts on 'milk per cow') which will vary by season. 'Imports and exports' influence 'dairy product inventories' and demand for dairy products is influenced by Population and Income Per Capita. Although exogenous effects are relevant, a 
key consideration in SD models is that the observed patterns of dynamic behavior for variables will depend primarily on the dominant endogenous feedback loop processes defined in the model structure, which also can vary over time.

\subsection{Model empirical representation}

The empirical model consists of a large number of stock-flow-feedback processes represented as a system of differential equations. The main stocks of the system are the cows on farm and its categories of young animals (calves and heifers) that are controlled by the herd parameters. The herd aging chain represents the main biological delay that affects the farm supply response. The genetic potential of the cows is also represented by a stock and affect the cow's productivity as an increasing trend function reflecting the inertia of the genetic gains observed in Brazil. Genetic potential can be increased by modifications on production practices and the observed cow production per day is also represented by a stock variable. The inventories of dairy products - fluid milk and beverages, soft products, storable products and balancing products comprising butter and powder milk - are the main stock in the post-farm supply chain. Inventory levels are determined by milk production on farms, processing capacity and costs, by the exogenous demand curve and elasticities, and by (exogenous) imports and exports. The relative inventory coverage (measured in months) affects the wholesale price of dairy products and consequently the farm milk price. The monthly farm milk price is the central stock of the system formed by a proportional fraction of all dairy products and is adjusted with a delay that represent an adaptive expectation that drive farm-level decision making. Further details of all stocks and flows and the auxiliary variables that control the system are provided in the Supplementary Chapter S1.

\subsection{Data}

The data used for model development include official sources, specialized literature and expert opinion. We interviewed fifteen specialists from different segments of the Brazilian and the US dairy industry and academic institutions to facilitate specification of parameter values and to assess the behavior over time of key variable. A detailed description of the process involving expert opinion is provided in the Supplementary Chapter S3. Many parameters (especially from the herd aging chain) were estimated based on Minas Gerais State as a proxy for the whole country when national data were not available. This assumption is reasonable because dairy production systems in Minas Gerais encompass a broad range of milk production systems (Simões et al., 2015; Zoccal et al., 2007), the state is the largest milk producer (around 25\% of the national total), and its price formation mechanisms, price behavior and processing capacity are representative of Brazil as a whole (Carvalho et al., 2014; Fernandes et al., 2010; Siqueira et al., 2010). The model was built using the software Vensim version DSS ${ }^{\circledR}$ that is a specific tool for system dynamics modeling. We choose 2005 as a base (initial) year because it corresponded to the year of publication of 'Brazilian agricultural census and the dairy livestock survey of Minas Gerais' by Gomes (2006).

\subsection{Scenarios analyzed}

Milk production systems are divided into five size categories according to daily production: less than 50 liters per day, 51 to 200, 201 to 500, 501 to 1000 and higher than 1000 liters per day. The main characteristics and initial parameters of milk production systems were obtained from the dairy livestock survey of Minas Gerais of 2005 (Gomes, 2006) and the technological improvements by changing the most relevant parameters based on other previous research (Camilo Neto et al., 2012; Fassio et al., 2006; Fassio et al., 2005; Nascif, 2008; Oliveira et al., 2007), the EDUCAMPO ${ }^{1}$ database from SEBRAE-MG and expert opinion. The technology improvement scenarios comprised a simultaneous change in a set of practices (i.e. a 'technology package') that modify efficiency parameters like calving interval, time required for heifer maturation, time to weaning, calf mortality, stocking rate (by forage type), milk production per cow, genetic composition, ${ }^{1}$ EDUCAMPO is a management and technologic assistance program to dairy farmers from the Brazilian Micro and Small Business Support Service
(SEBRAE). The EDUCAMPO database is confidential and was used with permission. 
labor efficiency and concentrated ration over milk production ratio. All costs and revenues for each sizecategory were modified based on the proposed system improvements also including the cow replacement cost. In the Supplementary Chapter S2 we provide a comprehensive description of the parameters used for non-adopters and adopters of technology.

Evidence from previous studies indicates that technology diffuses very slowly among dairy farmers in developing countries, with estimates ranging from $0.5 \%$ to $2.5 \%$ per year depending of the nature of the technology. In high-income countries, the speed of diffusion in the dairy industry can be faster, ranging from $6 \%$ to $21 \%$ per year (Batz et al., 1999). Our analyses examined three proportional annual rates of transition from current to improved technologies: slow (0.3\%), medium (1.65\%), and fast (3.0\%). These rates were assumed to apply to farms aggregated into two size-categories: small (production up to 200 1/day - the two smallest farm size categories) and large (production above 200 1/day - the four largest farm size categories). We assessed six scenarios in which either farms in either the small or large categories (but not both simultaneously) adopted technologies at each of the three assumed rates (Table 1).

\subsection{Model evaluation}

One component of model evaluation is the ability of the model to replicate observed behaviors of interest. The model replicated observed patterns of monthly farm milk prices, milk per cow, cow and total milk production from 2005 to 2016, which provides evidence that it is adequate for our research objectives. In addition, Sterman (2000) recommends 11 tests as best practices for SD models beyond replication of patterns in historical data. These tests assess the appropriateness of the underlying assumptions, robustness, and the sensitivity of results to assumptions about model boundary and feedback structure. We undertook selected components of these tests during model development. The discussion of the tests performed is provided in Supplementary Chapter S3 including the behavior reproduction of milk price, cow numbers, and monthly milk production.

\section{Results}

Our analysis covers the period from January of 2005 to December of 2016, and key outcomes include milk production, milk price and cow numbers. The baseline scenario of the simulation model replicated the patterns of behavior observed for these three variables. Milk production in Brazil has a consistent seasonal pattern and increased through late 2014. Nominal farm milk prices and milk per cow also increased through the study period, with seasonal fluctuations. In 2015 milk production decreased due to lower cow numbers, brought about by increased costs and lower profitability (Supplementary Chapter S1: Figures S1, S2 and S3). We report the results for technology adoption scenarios from three perspectives, first focusing on the average values for the whole period of analysis and with farm categories aggregation, then temporally-aggregated results disaggregated by farm size and finally temporally disaggregated results that indicated behavior over time.

Table 1. Six scenarios description considering the size category and the rate of transition from non-adopters to adopters. ${ }^{1}$

\begin{tabular}{llll}
\hline \multirow{2}{*}{ Farm size } & \multicolumn{4}{l}{ Adoption Rate (\% per year) } \\
\cline { 2 - 4 } & Slow (0.3) & Medium (1.65) & Fast (3.0) \\
\hline Small $(<200$ liters per day) & SS & SM & SF \\
Large $(>200$ liters per day) & LS & LM & LF \\
\hline${ }^{1}$ Example: SS indicates that $0.3 \%$ of farms in the small category (farms with production less than 200 1/day) adopted the improved \\
technology each year. LM indicates that $1.65 \%$ of farms in the large category (farms with production $>2001 /$ day) adopted the \\
improved technology each year.
\end{tabular}




\subsection{Aggregated results}

Technology adoption results in larger average milk per cow and annual milk production for all scenarios and consequently lower farm milk prices. Scenarios in which small farms adopt technology (SS, SM, SF) the average annual milk production increases due to increases in milk per cow, which more than offset the average decrease in cow numbers. For the scenarios in which larger farms improve their technology (LS, LM, LF), the average annual milk production increases due to increases in both milk per cow and cow numbers (Table 2). In all scenarios the average Net Farm Operating Income (NFOI) is lower than the baseline and additional aggregated interpretation and discussion is provided in Supplementary Chapter S4.

\subsection{Results by farm size categories}

Technology adoption increases the average NFOI of adopting farms and generally decreases NFOI for all nonadopting farms when compared with the Baseline. Thus, broad adoption of technologies focused on genetic improvements and strategic feeding would improve the individual profitability of farms despite the likely effect of lower milk prices but have a negative impact on non-adopters through price reduction. Therefore, the aggregated benefits of technology adoption would depend not only on the rate of adoption but also on the fraction of adopters in each farm-size category. For example, in the previous section the aggregated analysis indicates that in all scenarios of small farms adopting (SS, SM, and SF) the overall average NFOI is always lower than the baseline, however, the disaggregated interpretation indicates that the net benefits are lower for the non-adopters (larger and small farms) and higher for small farms that adopt technology. Similarly, for the scenarios which larger farms adopt technology (LS, LM, and LF), the aggregated analysis indicates that NFOI is always higher for adopting farms, but small farms experience decreased profitability and large farms that do not adopt benefit less than adopting farms. (Table 3).

Adoption of new technology influences NFOI in part through changes in milk per cow but also through changes in cows owned per farm. The number of cows per farm at the end of the simulation by farm size category is reduced for non-adopting farms and increased for adopters in all scenarios and sizes (Table 11A in Appendix). The assessment of cow numbers supports the hypothesis that the disaggregated analysis is important to understand aggregated behaviors. For instance, the observed cow number reduction in the SS, SM and SF scenarios (Table 2) is because the reduction of cows of non-adopting farms more than offsets the increasing cow numbers for adopting farms. For the scenarios LS, LM and LF, the observed increase of cow numbers at the aggregated level is due the higher magnitude of the increase of adopters in relation to the decreasing of non-adopters.

Table 2. Average values of aggregated farm-related outcome variables for the six scenarios of technology improvement and the difference from the baseline in percentages, based on averages from January 2006 to December 2016. ${ }^{1}$

\begin{tabular}{llllllll}
\hline & Baseline (units) & SS (\%) & SM (\%) & SF (\%) & LS (\%) & LM (\%) & LF (\%) \\
\hline Milk production (bil. 1/year) & 27.2 & 5.5 & 12.3 & 14.0 & 5.7 & 17.8 & 21.1 \\
Cows (Mil. heads) & 21.8 & -1.9 & -7.7 & -9.4 & 2.1 & 7.0 & 8.4 \\
Milk per cow (1/cow/year) & 1,247 & 7.5 & 21.7 & 25.9 & 3.5 & 10.1 & 11.7 \\
Farm milk price (R $\$$ /) & 0.85 & -3.7 & -9.5 & -10.9 & -3.4 & -10.2 & -12.8 \\
Average NFOI (R $/$ farm/month) & 1,013 & -8.4 & -21.7 & -25.7 & 39.2 & 80.2 & 74.1 \\
\hline
\end{tabular}

${ }^{1}$ Abbreviations: farm size (first letter): small (S), large (L); and adoption rate (second letter): slow (S), medium (M), fast (F). 
Table 3. Net farm operating income in Reals per month of each farm-size category, the baseline and the six scenarios, averages from January 2006 to December $2016 .{ }^{1}$

\begin{tabular}{llrrrrrrr}
\hline Category (R\$/farm/month) & Baseline & \multicolumn{1}{l}{ SS } & SM & SF & LS & LM & LF \\
\hline$<50$ 1/day & non-adopters & -2 & -24 & -13 & 48 & -24 & -69 & -85 \\
& adopters & - & 346 & 257 & 236 & - & - & - \\
\multirow{2}{*}{$51-200$ 1/day } & non-adopters & 144 & 48 & 13 & 132 & 56 & -113 & -171 \\
& adopters & - & 1,094 & 734 & 655 & - & - & - \\
\multirow{2}{*}{$201-500$ 1/day } & non-adopters & 1,634 & 1,250 & 745 & 637 & 1,306 & 774 & 757 \\
& adopters & - & - & - & - & 6,779 & 5,094 & 4,424 \\
\multirow{2}{*}{$501-1000$ 1/day } & non-adopters & 5,542 & 4,460 & 2,963 & 2,640 & 4,595 & 2,862 & 2,366 \\
& adopters & - & - & - & - & 16,948 & 13,320 & 11,910 \\
$>1000$ 1/day & non-adopters & 19,729 & 16,364 & 11,445 & 10,355 & 16,768 & 11,186 & 9,339 \\
& adopters & - & - & - & - & 49,884 & 39,773 & 35,946 \\
\hline
\end{tabular}

${ }^{1}$ Abbreviations: farm size (first letter): small (S), large (L); and adoption rate (second letter): slow (S), medium (M), fast (F).

\subsection{Distributional impacts of farm-level technology adoption}

Technology adoption could markedly affect the structure of Brazil's dairy sector. In the baseline the proportion of milk production of small farms ( $<200$ liters/day) and large farms ( $>200$ liters per day) at the end of the simulation was $25 \%$ and $75 \%$, respectively. Technology adoption by small farms (scenarios SS, SM, SF) increases the proportion of milk produced by small farms to much closer to half of total milk production (e.g. 43\%) under the assumption of the fastest rate of adoption. If technology is adopted by large farms, the proportion of milk production by large farms would reach nearly $90 \%$ for fastest rate of adoption (Figure 2). Our results also indicate that the structure of milk production (and therefore the income distribution for dairy farmers) is markedly influenced by which farms adopt and their rate of adoption. The proportion of milk produced by adopters and non-adopters at the end of simulation is similar across each size category given the fixed rate of adoption assumed. In scenarios of slow adoption rate the final proportion produced by non-adopters and adopters are $40 \%$ and $60 \%$ respectively, for medium adoption rate the proportions are $2 \%$ and $98 \%$, and for the fastest adoption rate all milk produced is provided by the adopters.

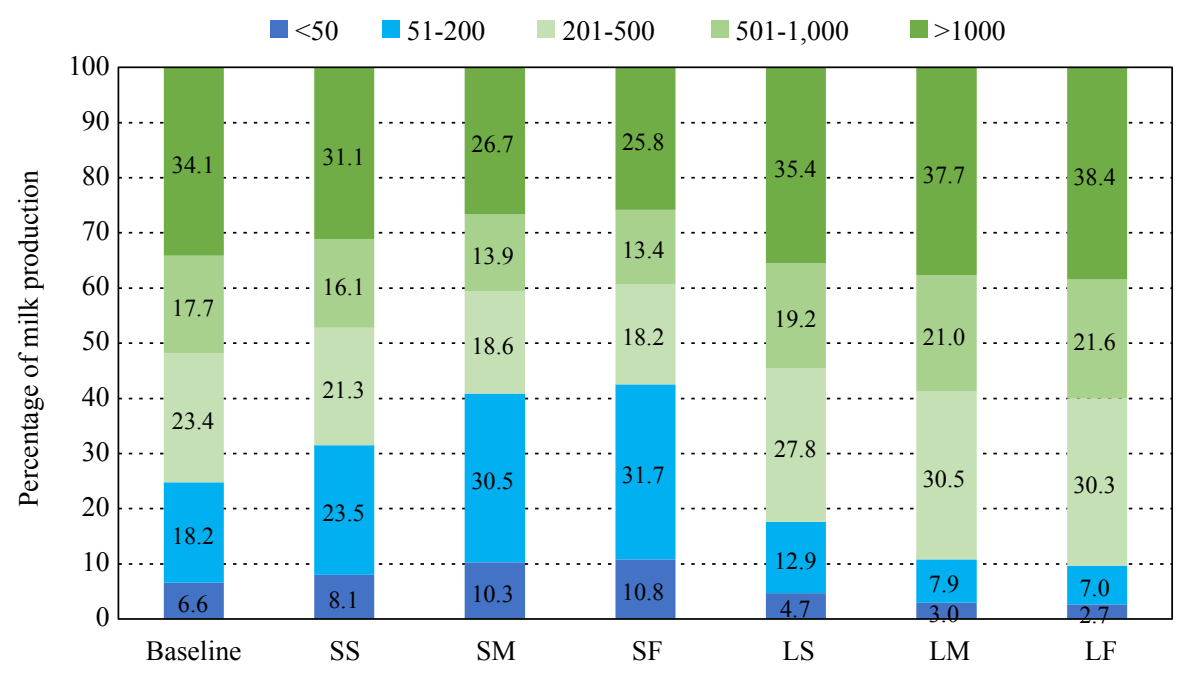

Figure 2. Percentage of annual milk production for each farm-size category for the baseline and the six scenarios in 2016. Abbreviations: farm size (first letter): small (S), large (L); and adoption rate (second letter): slow (S), medium (M), fast (F). 
Technology adoption also affects the distribution of NFOI. When small farms adopt technology (SS, SM, and SF), they experience a substantive increase in aggregated NFOI and the large farms (non-adopters) experience a less dramatic NFOI reduction. In scenarios LS, LM and LF, the NFOI increase is much larger and aggregate NFOI for small non-adopter farms is negative (Figure 3).

Thus, our analysis suggests that public or private efforts for dairy sector development through technology adoption will have different impacts depending on which farms are a focal point for efforts to promote technology adoption. Although useful, this information in and of itself does not suggest the preferred strategy for such dairy sector development efforts. This is in part because our scenarios indicate that there are no Pareto-superior outcomes in which all farms experience increased NFOI. This implies that some farms would be made better off through technology adoption and others worse off, posing a policy choice. In addition, relevant costs that would affect outcomes (such as transactions, transportation and transition costs) have not been accounted for in this analysis, and inclusion of the costs could affect which scenarios are preferred. Finally, we have not assessed the programmatic costs or feasibility of achieving the assumed adoption rates, which in reality would affect the observed outcomes.

Previous research highlights that technology adoption is a major determinant of structural change in dairy farming. According to El-Osta and Morehart (2000) and Quiroga and Bravo-Ureta (1992) technological advances produce a smaller number of larger-sized farms with higher productivity and lower unit production costs. Weersink and Tauer (1991) examined the causality between farm size in the US and profitability using causality tests. Their results only partially support the view that technological change has caused increases in dairy farm size. For them, the direction of causality appears to be more from size to productivity. Changes in productivity and average herd size also appears to be driven by price changes. In this case - and aligned with our dynamic hypothesis (Figure 1) - faster technology adoption rates result in higher profitability of adopters, which motivates lower culling rates and results in more cows per farm. Consequently, larger adopting farms may displace small and non-adopters from their current market share via the impacts of increased aggregate milk production on prices and small-farm profitability. This aligns with the observation of Feder et al. (1985) that the early adopters (usually the larger and wealthier farms) can accumulate more wealth and thus acquire more land from the non-adopters. The acquisition of new wealth enables further adoption and thus affects the dynamic pattern of aggregate adoption. Thus, particular attention to changes in landholding patterns and wealth accumulation probably is warranted for Brazil's dairy sector in the case of widespread adoption of new technologies.

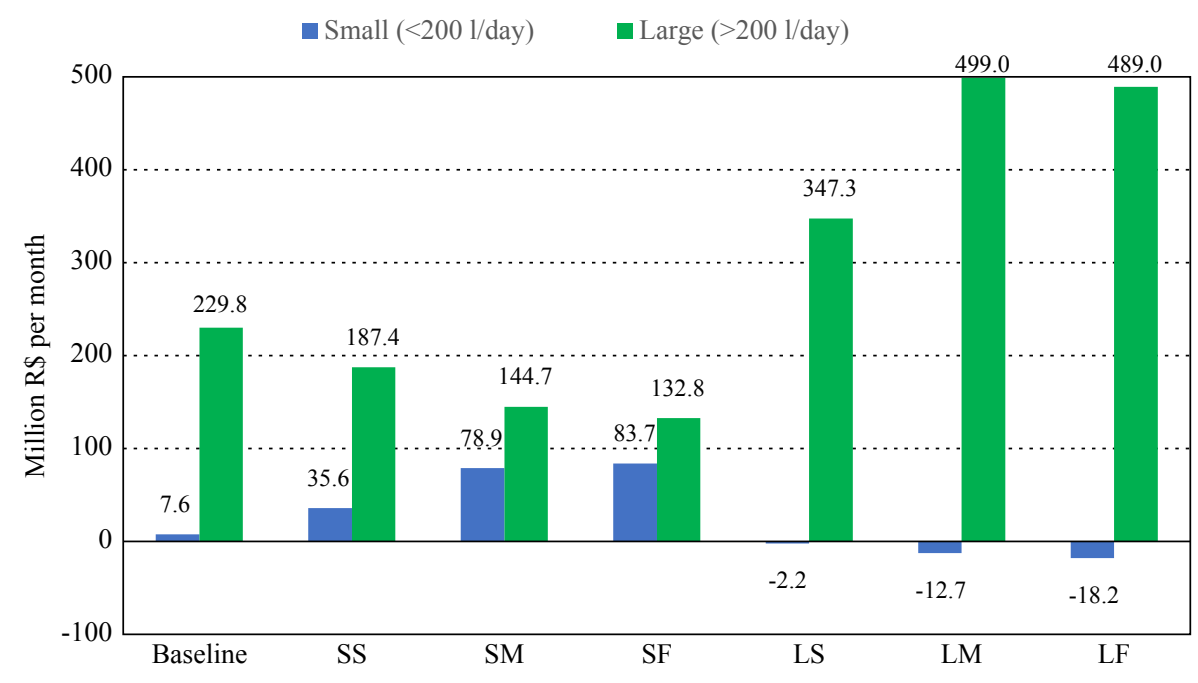

Figure 3. Net farm operating income for each farm-size category for the baseline and the six scenarios in 2016. Abbreviations: farm size (first letter): small (S), large (L); and adoption rate (second letter): slow (S), medium (M), fast (F). 


\subsection{Temporally disaggregated results}

Milk prices are on average relatively low (-8.4\%) in technology adoption scenarios due to the increase in milk supply (based on the scenarios shown in Table 2). However, the decrease in prices with technology adoption varies over time. The gap in milk prices between the baseline and scenarios of the medium and fast adoption rate is widest in the middle of the simulation period, then closes after 2013 (Figure 4). This gap illustrates dynamic complexity in Brazil's dairy sector. In the short-run, prices are the most negatively affected, but with completion of the adoption process, dynamic adjustments in cow numbers and demand that play out over longer time frames reduce the size of the gap in the long run. This dynamic is similar to the dynamic behavior found by Nicholson and Stephenson (2015). When technology adoption was simulated at different rates by Weersink and Tauer (1990) in selected US regions, prices become generally lower in the early simulation period and then increased, with consequent effects on net income and the value of quasifixed assets like cows and labor. Our scenarios demonstrate further details beyond the temporal complexity. Technology adoption and higher profitability of large adopting farms could result in lower profitability for small non-adopters via price effects. This is in agreement with what Weersink and Tauer (1990) determined for contrasting different milk production regions in the US.

All non-adopting farms experience decreased NFOI when compared with the baseline, except for the category of $<50$ liters per day (Table 3). The temporally disaggregated analysis indicates that the NFOI is lower than the baseline until late 2013 and then becomes higher for the $<50$ liters per day category (Figure 5) and for 51-200 liters per day (not represented), however, the resulting average NFOI for the first is significantly higher and slightly lower (-8\%) for the latter. These results are related to the herd composition in these two periods (before and after 2012-13). Reduction in cow numbers result in lower total revenue but also lower costs, resulting in a less negative NFOI towards the end of simulation. This suggests that the negative impacts on NFOI for non-adopters, similar to farm milk prices, exhibit dynamic complexity (worse before better behavior). It is also worth noting that adoption per se does not prevent lower (and negative) NFOI values for adopting farms beginning in 2015.

The negative NFOI values occur more frequently later in the simulation, exactly when one would expect that technology adopters evolved to a better profitability situation. This is due to the increase in production

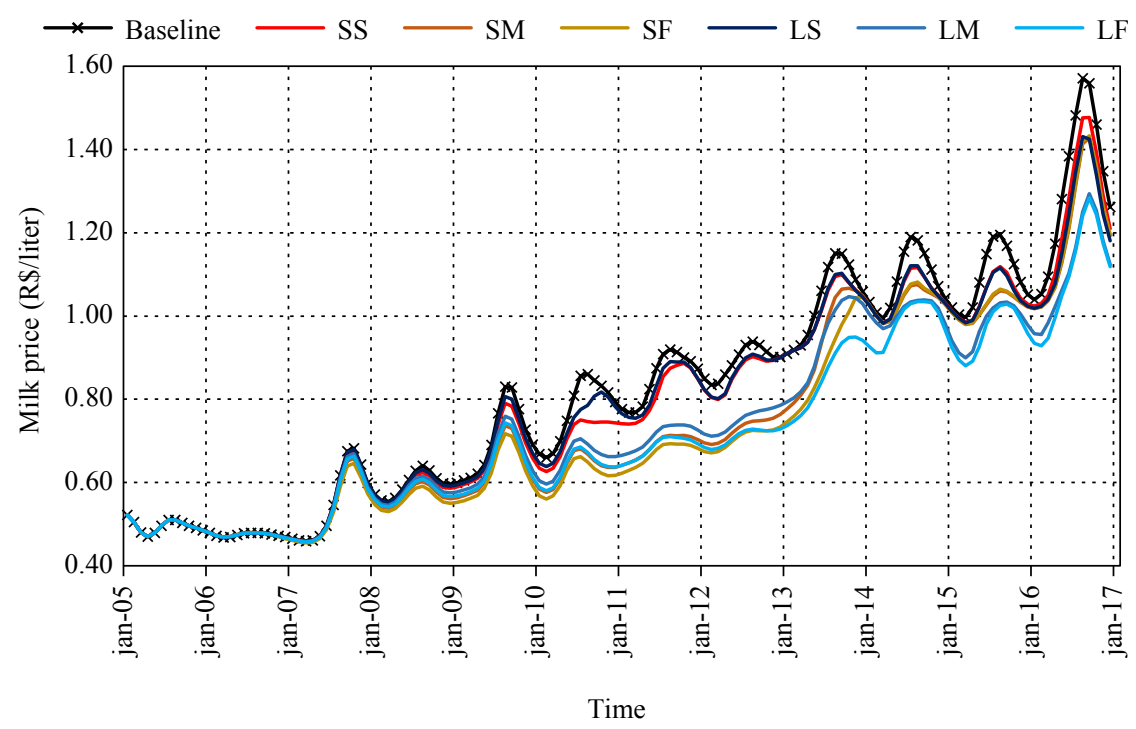

Figure 4. Average milk price for aggregated farm-size categories in the baseline and the six scenarios, from January 2005 to December 2016. The exchange rate R \$ to USD was 3.26 in December 2016. Abbreviations: farm size (first letter): small (S), large (L); and adoption rate (second letter): slow (S), medium (M), fast (F). 


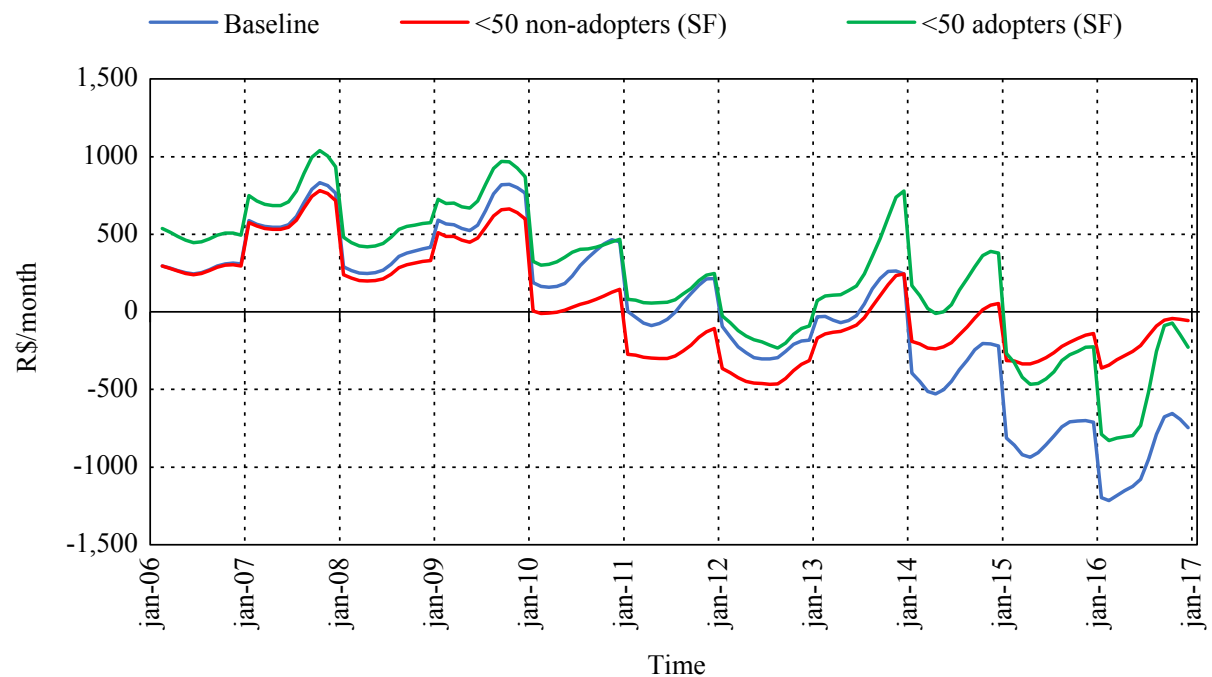

Figure 5. Net farm operating income for farms up to 50 liters per day in the scenarios of fast technology adoption, from January 2006 to December 2016.

costs (especially the exogenous ration price, which increased more later in the simulation period) and with the long-term adjustment of milk price. We found that the frequency of negative NFOI values increases for non-adopters and markedly decreases when technology is adopted in all scenarios and size categories, for instance for the category of 501-1000 liters per day (Figure 6). This is a positive aspect of technology adoption related to the increase of NFOI. Even with more variation over time experienced by large adopting farms, the variation occurs with a higher average level, resulting in less frequent negative value of NFOI. The frequency of negative NFOI is reduced for small adopting farms but remains higher than that for large adopting farms (based on comparisons of Figure 5 and Figure 6).

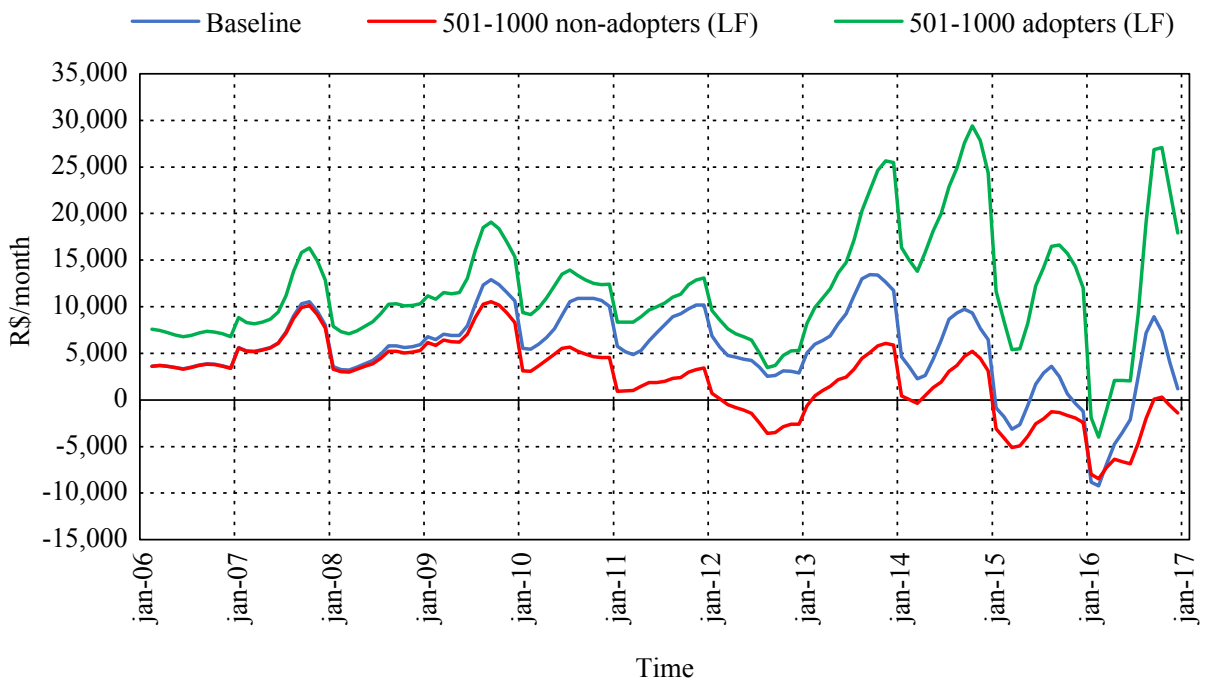

Figure 6. Net farm operating income for farms of 500-1000 per day in the scenarios with rapid technology adoption, from January 2006 to December 2016. 


\section{Conclusions}

Widespread technology adoption would likely result in higher milk production in Brazil and consequently lower prices. However, the specific impacts on dairy farms vary considerably when the focus of technological changes varies by farm size and with the speed of adoption. Market changes due to productivity-enhancing technologies affect farm profitability and farmers' decisions about their herd size and production practices over time. From a farm management perspective, our analyses indicate adopters always prosper relative to non-adopters; it is profitable to adopt these technologies even with the offsetting effects on prices because of lower unit costs of production. Non-adopters of technology can experience lower incomes and a smaller production and income shares when other farms adopt. The underlying causal structure of farm profitability and the herd management decisions suggests the potential market exclusion (i.e. farm exits) of non-adopting farms (especially small farms) when others adopt. The counterfactual scenarios of technology adoption indicate that, in the presence of delays and non-linear feedback responses, dynamic complexity will affect the magnitude and timing of farm outcomes, for instance, the worse-before-better behavior of farm profitability for some farms. Agricultural researchers who develop and promote such technologies tend to focus on firmlevel benefits but may not be aware or mindful of potential industry-level (market) effects. Persistent use of a new technology clearly implies that successful adopters achieve a net benefit, but non-adopters will face reduced profitability, and some will exit as a result. Assuming no complicating changes in product quality, the principal beneficiaries of supply-shifting technology adoption will be the buyers of milk along the supply chain. Although not considered explicitly here, assessment of the firm and industry merits of productivityincreasing technologies should also take into account the possibility that other sectors or sources of product will cause consumer, or even processor, demand to shift. Industry strategy and the policy decisions that relate to alternative sectors and research investment involve many considerations, including who ultimately benefits from production-enhancing technologies, such as what technologies should be promoted for adoption by which farms, with what (societal) objectives? This research highlights the different firm and industry impacts, in magnitude and over time, for hypothetical productivity-enhancing technologies. Our analyses would be complemented by additional work on the costs and benefits of specific, alternative dairy industry public investment strategies. The results strongly suggest that costs and benefits must go well beyond the short run effects for adopters vs. non-adopters.

\section{Supplementary material}

Supplementary material can be found online at https://doi.org/10.22434/IFAMR2019.0033.

Chapter S1. Model description

Chapter S2. Scenarios

Chapter S3. Model evaluation - test performed

Chapter S4. Additional interpretation of aggregated results

Chapter S5. List of equations and parameters

\section{References}

Asres, A., J. Sölkner, R. Puskur, and M. Wurzinger. 2012. Livestock innovation systems and networks: Findings from smallholder dairy farmers in Ethiopia. Livestock Research for Rural Development 24 (9): 13.

Batz, F.-J., K. Peters and W. Janssen. 1999. The influence of technology characteristics on the rate and speed of adoption. Agricultural Economics 21 (2): 121-130. https://doi.org/10.1016/S0169-5150(99)00026-2.

Baumgart-Getz, A., L.S. Prokopy and K. Floress. 2012. Why farmers adopt best management practice in the United States: a meta-analysis of the adoption literature. Journal of Environmental Management 96 (1): 17-25. https://doi.org/10.1016/J.JENVMAN.2011.10.006.

Bhattacharya, P., B. N. Rath and A.K. Dash. 2016. Supply response of milk production: analysis and implications for BRIC countries. Applied Econometrics and International Development 16 (1): 179-192. 
Bozic, M., C. Wolf and F. Yang. 2014. What do dairy producers think about the margin protection program? working paper 13-05. Available at: https://dairymarkets.org/PubPod/Pubs/WP14-05.pdf.

Breitenbach, R. 2018. Economic viability of semi-confined and confined milk production systems in freestall and compost barn. Food and Nutrition Sciences 09 (05): 609-618. https://doi.org/10.4236/ fns.2018.95046.

Camilo Neto, M., J.M. de S. Campos, A.S. de Oliveira and S.T. Gomes. 2012. Identification and quantification of benchmarks of milk production systems in Minas Gerais. Revista Brasileira de Zootecnia 41 (10): 2279-02288.

Campos, S.A.C., A.B. Coelho, A.P. Gomes and L.B. de Mattos. 2014. Efficiency and costs associated to environmental adequacy for milk production in Minas Gerais, Brazil. Organizações Rurais \& Agroindustriais 16 (3): 324-342.

Carvalho, B.H.P., P.L. Rosado, S. de F.N. Shiki and A.C. Cruz. 2014. Integração intra e inter-mercado: o caso dos preços do leite e derivados no Brasil. Anais Do XLI Encontro Nacional de Economia 19.

Chavas, J.-P. and R.M. Klemme. 1986. Aggregate milk supply response and investment behavior on U.S. dairy farms. American Journal of Agricultural Economics 68 (1): 55-66. https://doi.org/10.2307/1241649.

El-Osta, H.S. and M.J. Morehart. 2000. Technology adoption and its impact on production performance of dairy operations. Review of Agricultural Economics 22 (2): 477-498. http://www.jstor.org/stable/1349806.

FAO. 2018. FAOSTAT: food and agricultural commodities production; commodity per country. Available at: http://www.fao.org/faostat/en/\#home.

Fassio, L.H., R.P. Reis and L.G. Geraldo. 2006. Desempenho técnico e econômico da atividade leiteira em Minas Gerais. Ciência e Agrotecnologia 30 (6): 1154-1161. https://doi.org/10.1590/S141370542006000600018.

Fassio, L.H., R.P. Reis, L.C.T. Yamaguchi and A.J. dos Reis. 2005. Custos e shut-down point da atividade leiteira em Minas Gerais. Revista de Economia e Sociologia Rural 43 (4): 759-777. https://doi. org/10.1590/S0103-20032005000400007.

Feder, G. and D.L. Umali. 1993. The adoption of agricultural innovations: a review. Technological Forecasting and Social Change 43 (3-4): 215-239. https://doi.org/10.1016/0040-1625(93)90053-A.

Feder, G., R.E. Just and D. Zilberman. 1985. Adoption of agricultural innovations in developing countries: a survey. Economic Development and Cultural Change 33 (2): 255-298. https://doi.org/10.1086/451461.

Fernandes, R.A.S., M.J. Braga and J.E. de Lima. 2010. Elasticidade de transmissão e formação espacial de preços de leite ao produtor nos maiores estados produtores. Revista de Economia e Administração 9 (3): 368-385.

Fuglie, K.O., P.W. Heisey, J.L. King, C. Pray, K.D. Rubenstein, D.E. Schimmelpfennig, S.L. Wang and R. Karmarkar-Deshmukh. 2011. Research investments and market structure in the food processing, agricultural input, and biofuel industries worldwide. USDA-ERS economic research report no. 130. Available at: https://papers.ssrn.com/sol3/papers.cfm?abstract_id=2027051\#\#.

Gomes, S.T. 2006. Diagnóstico Da Pecuária Leiteira Do Estado de Minas Gerais Em 2005. Available at: https://tinyurl.com/y4jb3c53.

Howley, P., C.O. Donoghue and K. Heanue. 2012. Factors affecting farmers' adoption of agricultural innovations: a panel data analysis of the use of artificial insemination among dairy farmers in Ireland. Journal of Agricultural Science 4 (6): 171. https://doi.org/10.5539/jas.v4n6p171.

Instituto Brasileiro de Geografia e Estatística - IBGE. 2017. Censo Agropecuário. Available at: https:// censos.ibge.gov.br/agro/2017.

Johnson, N.L. and V.W. Ruttan. 1997. The diffusion of livestock breeding technology in the U.S.: observations on the relationship between technical change and industry structure. Journal of Agribusiness 15: 19-35.

Meadows, D.L. 1970. Dynamics of commodity production cycles. Pegasus Communications, Waltham, MA, USA.

Nascif, C. 2008. Indicadores técnicos e econômicos em sistemas de produção de leite de quatro Mesorregiões do Estado de Minas Gerais. Universidade Federal de Viçosa. Available at: https://preview.tinyurl. $\mathrm{com} / \mathrm{y} 3 \mathrm{v} 3 \mathrm{yxd} 6$.

Nicholson, C.F. and M.W. Stephenson. 2010. Analysis of proposed programs to mitigate price volatility in the U.S. dairy industry. Available at: http://www.futurefordairy.com/pdfs/Nicholson-and-StephensonAnalysis.pdf. 
Nicholson, C.F., and M.W. Stephenson. 2014. Modeling government intervention in agricultural commodity markets: U.S. dairy policy under the agricultural act of 2014. Plenary paper. $32^{\text {nd }}$ International Conference of the System Dynamics Society, Delft, the Netherlands, 20-24 July 2014. Available at: https://www.systemdynamics.org/assets/conferences/2014/proceed/papers/P1191.pdf.

Nicholson, C.F., and M.W. Stephenson. 2015. Milk price cycles in the U.S. dairy supply chain and their management implications. Agribusiness: An International Journal 31 (4): 507-520. https://doi. org/10.1002/agr.21416.

Novo, A.M., M. Slingerland, K. Jansen, A. Kanellopoulos and K.E. Giller. 2013. Feasibility and competitiveness of intensive smallholder dairy farming in Brazil in comparison with soya and sugarcane: case study of the Balde Cheio Programme. Agricultural Systems 121 (0): 63-72. https://doi.org/10.1016/j. agsy.2013.06.007.

Olaya, C. 2015. Cows, agency, and the significance of operational thinking. System Dynamics Review 31 (4): 183-219. https://doi.org/10.1002/sdr.1547.

Oliveira, A.S. de, D. de N.F.V. da Cunha, J.M. de S. Campos, S.M.L.R. do Vale and A.J. de Assis. 2007. Identificação e quantificação de indicadores-referência de sistemas de produção de leite. Revista Brasileira de Zootecnia 36 (2): 507-516. https://doi.org/10.1590/S1516-35982007000200030.

Oliveira, M.V.M., O.F.N. e Sá, C.L. de Abreu, D.P. de Oliveira, A.R.P. Simoes, F.M. de V. Junior, D.F. Luz, and P. Maltempi Filho. 2015. Dairy calves fed with milk replacer in substitution to whole milk. Agrarian 8 (30): 405-413.

Parsons, D. and C.F. Nicholson. 2017. Assessing policy options for agricultural livestock development: a case study of Mexico's sheep sector. Cogent Food \& Agriculture 3 (1) https://doi.org/10.1080/233 11932.2017.1313360.

Quiroga, R.E., and B.E. Bravo-Ureta. 1992. Short- and long-run adjustments in dairy production: A profit function analysis. Applied Economics 24 (6): 607-616. https://doi.org/10.1080/00036849200000029.

Silva, L.H.A. da, M.R.G. da Camara, and T.S. Telles. 2016. Evolution and spatial distribution of dairy production in Paraná State, Brazil. Acta Scientiarum. Human and Social Sciences 38 (1): 37-47. https://doi.org/10.4025/actascihumansoc.v38i1.30006.

Simões, A.R.P., V.P. Silva Junior and R.M. Protil. 2015. Technologic profile of dairy farming in Minas Gerais. $53^{\circ}$ Congresso Da Sociedade Brasileira de Economia Administração e Sociologia Rural - SOBER 15.

Simões, A.R.P., J.D. dos Reis, and P.S. Avelar. 2017. The Technological heterogeneity of dairy farming in Minas Gerais. Agrarian 10 (38): 261-269. https://doi.org/10.30612/agrarian.v10i37.6782.

Siqueira, K.B., R.L. Kilmer and A.C. Campos. 2010. The dynamics of farm milk price formation in Brazil. Revista de Economia e Sociologia Rural 48 (1): 41-61. https://doi.org/10.1590/S010320032010000100003.

Spielman, D.J. 2005. Innovation systems perspectives on developing-country agriculture: a critical review. International Food Policy Research Institute, Washington, DC, USA.

Sterman, J.D. 2000. Business dynamics: systems thinking and modeling for a complex world. Mcgraw-Hill Education, New York, NY, USA.

Telles, T.S., M.D. Bacchi and J. Shimizu. 2017. Spatial distribution of microregions specialized in milk production. Semina: Ciências Agrárias 38 (1): 443-454. https://doi.org/10.5433/16790359.2017v38n1p443.

Verner, C. and P.M. Gubbels. 1967. The adoption or rejection of innovations by dairy farm operators in the lower fraser valley. Agricultural Economics Research Council of Canada (11):88.

Weersink, A. and L. Tauer. 1990. Regional and temporal impacts of technical change in the U.S. dairy sector. American Journal of Agricultural Economics 72 (4): 923-934. https://doi.org/10.2307/1242624.

Weersink, A., and L.W. Tauer. 1991. Causality between dairy farm size and productivity. American Journal of Agricultural Economics 73 (4): 1138-1145. https://doi.org/10.2307/1242442.

Zepeda, L., L.J. Butler and H.O. Carter. 1991. Simulating BST Introduction in california for dairy policy analysis. Western Journal of Agricultural Economics 16 (2): 228-237,.

Zoccal, R., A.V. Cerneiro, G. Carvalho, L.A. Stock, H. Chaib Filho and F.L. Garagorry. 2007. Distribuição espacial da pecuária leiteira no Brasil. Reunion Latino Americana de Produccion Animal (ALPA) 4. 